\title{
Evidence for a Radical Mechanism in Cu(II)-Promoted SnAP Reactions
}

\author{
Michael U. Luescher ${ }^{1}$ (D) \\ Jeffrey W. Bode* (1)
}

Laboratory of Organic Chemistry (LOC), Department of Chemistry and Applied Biosciences (D-CHAB), ETH Zurich, 8093 Zurich, Switzerland

bode@org.chem.ethz.ch

Dedicated to a great mentor and teacher - Rick L. Danheiser

Published as part of the 30 Years SYNLETT - Pearl Anniversary Issue
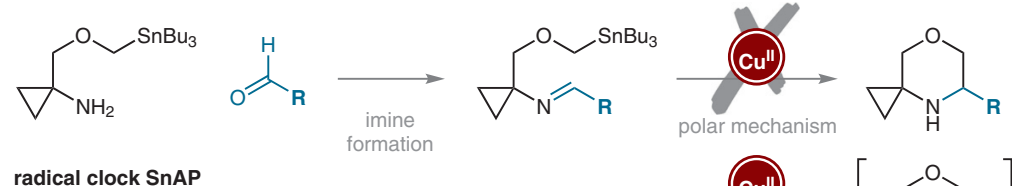

- $\mathrm{Cu}(\mathrm{II})$ ! A Lewis acid, transmetalating agent, or C-Sn bond oxidant?
Received: 14.12.2018

Accepted after revision: 10.01.2019

Published online: 05.02 .2019

DOI: 10.1055/s-0037-1611670; Art ID: st-2018-b0805-I

License terms: cc)

Abstract Saturated nitrogen heterocycles can be found with increasing abundance in bioactive molecules despite a limited number of methods to access these scaffolds. However, the coupling of recently introduced SnAP [tin (Sn) amine protocol] reagents with a wide range of aldehydes and ketones has proven to be a reliable, practical, and versatile one-step approach to saturated $\mathrm{N}$-heterocycles. While effective, the lack of mechanistic understanding limits efforts to develop new catalytic and enantioselective variants. To distinguish between a polar or radical mechanism, we assessed Lewis and Brønsted acids, radical trapping experiments, and radical clock SnAP reagents reinforcing the current understanding of the SnAP protocol as a radical cyclization.

Key words SnAP reagents, N-heterocycles, morpholines, cyclization, radical clock, mechanism

Tin (Sn) amine protocol (SnAP) reagents are simple building blocks used for the direct transformation of aldehydes and ketones into saturated five- to nine-membered $\mathrm{N}$-heterocycles such as substituted unprotected pyrrolidines, (thio)morpholines, piperazines, piperidines, oxazepanes, and diazepanes (Scheme 1). ${ }^{2}$ The SnAP protocol is distinguished by a broad substrate scope tolerating aromatic, heteroaromatic, and aliphatic aldehydes, including substrates bearing various functional groups such as unprotected indoles, phenols, esters, nitriles, and halides under simple, robust, and consistent reaction conditions.

The key $\mathrm{C}-\mathrm{C}$ bond forming reaction featured in SnAP chemistry relies on the addition of an organotin species to an imine, an underutilized transformation because of the poor electrophilicity of unfunctionalized and therefore unactivated imines. Circumventing the poor electrophilicity of imines through the use of an intramolecular reaction and avoiding the fundamental problems that are associated with the addition of strong nucleophiles to $\mathrm{C}=\mathrm{N}$ functionalities, e.g. aza-enolization or poor functional group tolerance, ${ }^{3}$ SnAP reagents with their $\alpha$-heteroatom $\mathrm{C}\left(\mathrm{sp}^{3}\right)-\mathrm{Sn}$ nucleophiles have emerged as valuable tools in the preparation of functionalized unprotected saturated heterocycles suitable for immediate further elaboration. ${ }^{2}$

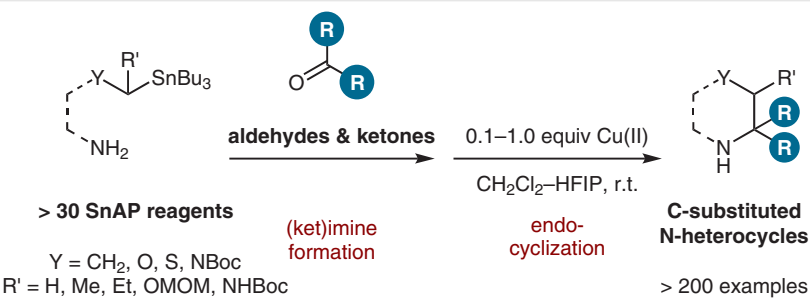

Scheme 1 SnAP chemistry: Cu(II)-mediated preparation of unprotected functionalized saturated nitrogen heterocycles

Circumstantial evidence, including the reluctance of chelating imines as $\mathbf{3}$ to participate in the reaction (Scheme 2 , a) and the ability to conduct the SnAP chemistry under photocatalytic conditions, ${ }^{4}$ strongly supports a radical mechanism. We have therefore favored a mechanistic scheme for the $\mathrm{Cu}$-promoted reactions in which $\mathrm{Cu}^{\mathrm{II}}$ acts as a one-electron oxidant. ${ }^{2 a}$ While this radical-based mechanism for the SnAP reagents rationalizes most of the observations, further studies were required to strengthen our proposal.

We have previously shown that substoichiometric amounts of radical inhibitors such as BHT or TEMPO retarded the reaction and alkoxamines arising from possible intermediate radicals were obtained by using stoichiometric amounts of TEMPO. ${ }^{2 a}$ With use of SnAP M for the preparation of morpholines rather than SnAP TM for the preparation of thiomorpholines as in our original publication, the 
radical inhibitor experiments were repeated here by using SnAP reagents with lower oxidation potentials (Scheme 2, b) and similar results were obtained.

Although the observation of alkoxyamine adduct $\mathbf{5}$ from the addition of TEMPO is indicative of a radical process, it could also arise from an unproductive side reaction, such as the disproportionation of an organo-copper intermediate after transmetalation or trapping of an oxonium after further redox reactions., ${ }^{5,6}$ Bærends, for example, has shown that $\mathrm{CuX}_{2}$.TEMPO can behave as an ionic electrophile by single-electron pairing of $\mathrm{CuX}_{2}$ and TEMPO forming a reactive oxidant that releases $\mathrm{Cu}(\mathrm{I})$ and a nucleophile-TEMPO adduct after the reaction with a two-electron nucleophile. ${ }^{7}$ The isolation of such an adduct might therefore represent a side reaction that is not connected to the productive $\mathrm{Cu}(\mathrm{II})-$ mediated conversion, emphasizing the need for additional experiments aimed at elucidating the mechanism of the SnAP reaction.

Furthermore, a Lewis acid-mediated mechanism can be excluded on the basis of the aforementioned experiments and failure to afford the desired product in previous experiments. However, investigations aimed at separating Lewis and Brønsted acid mechanisms needed to be carried out to further exclude a polar mechanism because $\mathrm{Cu}(\mathrm{OTf})_{2}$ with its weakly coordinating counterions is known to be a source of triflic acid (TfOH) acting as a Brønsted acid under conditions proposed to involve metal catalysis. ${ }^{8}$
In this report, we describe our investigations into further separating $\mathrm{H}^{+}$- and Lewis acid-mediated mechanisms from a reaction pathway involving single-electron species with a radical clock SnAP reagent aimed to trap possible intermediate radicals further down the reaction after a successful cyclization.

As a Lewis acid-mediated mechanism was excluded in earlier experiments, ${ }^{2 \mathrm{a}, \mathrm{b}}$ investigations aimed at elucidating the possibility of a Brønsted acid-mediated SnAP reaction mechanism were carried out (Table 1 ).

The standard SnAP reaction (Table 1, entry 1 ) involves the addition of stoichiometric quantities of a weak base, 2,6-lutidine, that is proposed to act as a ligand and form the active copper species. Leaving out 2,6-lutidine, which could interfere with a potential Brønsted acid-mediated mechanism, resulted in a decreased yield of the desired product 7 (entry 2). Furthermore, other Lewis acids known to be a source of triflic acid ${ }^{8}$ were unsuccessful in mediating the SnAP cyclization leaving $\mathrm{Cu}(\mathrm{OTf})_{2}$ as the sole active mediator under these conditions (entries 2-5). To further dismiss a Brønsted acid-mediated mechanism, the addition of excess 2,6-di-t-butylpyridine, a weak base that binds protons but is unable to coordinate to metal centers because of the sterically demanding $t$-butyl groups, ${ }^{9}$ only retarded the reaction, affording the desired product in moderate amounts (entry 6). Experiments in which TfOH was used in place of

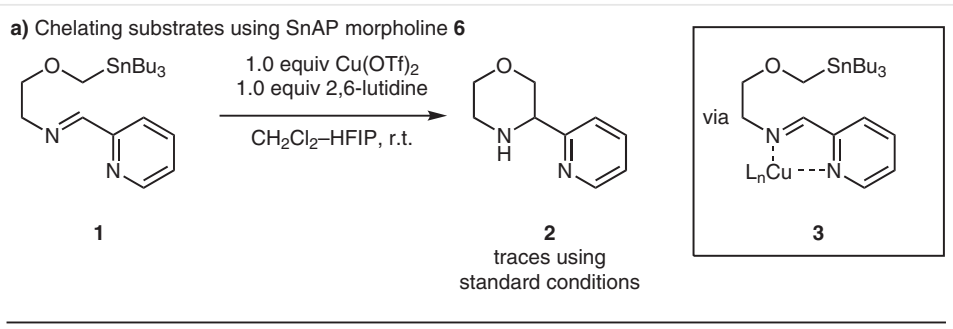

b) Proposed radical mechanism using SnAP reagents with isolation of TEMPO adduct 5

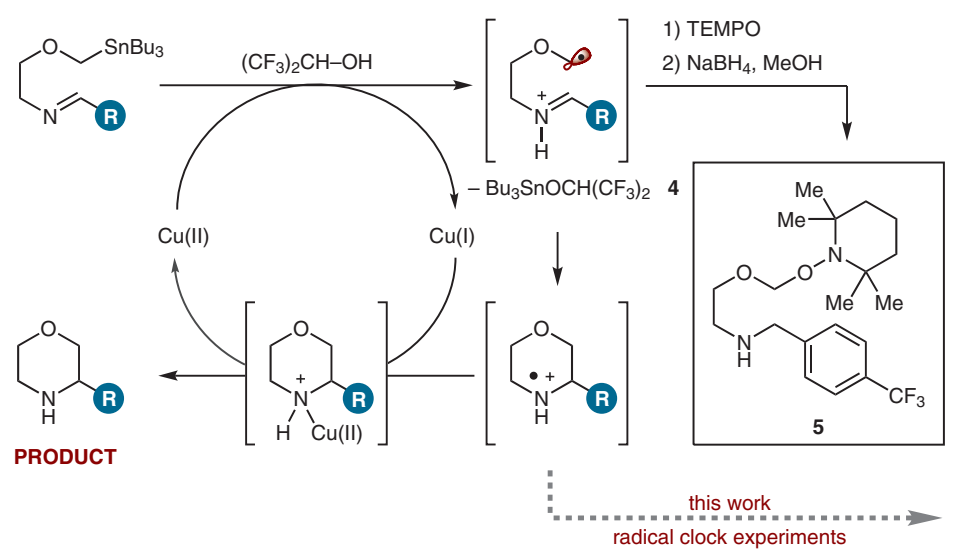

Scheme 2 Experiments supporting a role for $\mathrm{Cu}(\mathrm{OTf})_{2}$ as an oxidant rather than as a Lewis acid; see Supporting Information for more detailed TEMPO and BHT studies 
Table 1 Screening for Brønsted Acid-Mediated Cyclization

\begin{tabular}{|c|c|c|}
\hline Entry & Conditions $^{\mathrm{a}}$ & Results $^{b}$ \\
\hline $1^{\mathrm{c}}$ & $\begin{array}{l}\mathrm{Cu}(\mathrm{OTf})_{2}(1.0 \text { equ } \\
\text { (1.0 equiv) }\end{array}$ & $88 \%$ with $100 \%$ conv. \\
\hline 2 & $\mathrm{Cu}(\mathrm{OTf})_{2}(1.0 \mathrm{equ}$ & $65 \%$ with $100 \%$ conv. \\
\hline 3 & $\mathrm{Bi}(\mathrm{OTf})_{3}(1.0$ equi & $\leq 5 \%$ with $\leq 10 \%$ conv. \\
\hline 4 & $\mathrm{Yb}(\mathrm{OTf})_{3}(1.0 \mathrm{equ}$ & $\leq 5 \%$ with $\leq 5 \%$ conv. \\
\hline 5 & $\mathrm{Sc}(\mathrm{OTf})_{3}(1.0$ equi & $\leq 5 \%$ with $\leq 5 \%$ conv. \\
\hline 6 & $\begin{array}{l}\mathrm{Cu}(\mathrm{OTf})_{2}(1.0 \text { equi } \\
\text { ( } 2.5 \text { equiv })\end{array}$ & $21 \%$ with $30 \%$ conv. \\
\hline 7 & TfOH (1.0 equiv) & $\leq 5 \%$ with $28 \%^{d}$ \\
\hline 8 & TfOH (2.5 equiv) & ca. $5 \%$ with $52 \%$ d \\
\hline 9 & TfOH (2.5 equiv) $)^{\mathrm{e}}$ & $6 \%$ with $48 \%{ }^{d}$ \\
\hline 10 & TfOH (5.0 equiv) & ca. $6 \%$ with $93 \%$ d \\
\hline
\end{tabular}

a Reactions were conducted on a $0.15 \mathrm{mmol}$ scale at $23^{\circ} \mathrm{C}$ for $8 \mathrm{~h}$ in $\mathrm{CH}_{2} \mathrm{Cl}_{2}$-HFIP (4:1, $\left.0.05 \mathrm{M}\right)$.

b NMR yields and conversion (conv.) from ${ }^{1} \mathrm{H}$ NMR spectroscopic measurements of unpurified reaction mixtures with 1,3,5-trimethoxybenzene as an additional internal standard added after the reaction.

c Standard SnAP conditions.

I Imine hydrolysis as a side reaction.

e Slow addition over $8 \mathrm{~h}$.

$\mathrm{Cu}(\mathrm{OTf})_{2}$ afforded some product (entries 7-10). Although $\mathrm{Cu}(\mathrm{OTf})_{2}$ is known to be a source of slowly released TfOH in certain protic reaction media, there seems to be no correlation between the addition of $\mathrm{TfOH}$ at the beginning of the reaction or over the course of it (entries 8-10). This indicates that, although some product formation through a $\mathrm{H}^{+}-$ mediated mechanism could occur, on the basis of our current understanding we exclude polar mechanisms as the principal source of product formation.

Excluding a Lewis or Brønsted acid-mediated mechanism, we started looking more closely into the idea of $\mathrm{Cu}(\mathrm{OTf})_{2}$ acting as an oxidant, as proposed in the seminal SnAP publication. ${ }^{2 a}$ The main side product isolated seems to arise from intermediates in which the $\mathrm{C}-\mathrm{Sn}$ bond was oxidized to give an oxonium (Scheme 3). A free radical intermediate, which could arise through direct C-Sn bond oxidation or the disproportionation of in situ formed organocopper intermediate after transmetalation (rather than the involvement of a polar two-electron species), was further supported through the loss of stereochemical information in reactions using $\alpha$-bis substituted SnAP reagents. Racemic SnAP reagents bearing both a heteroatom and an alkyl substituent next to the organostannane group undergo stereoconvergent cyclizations in combination with enantiopure
PhBox ligands. ${ }^{2 e}$ Likewise, enantiomerically enriched $\alpha$-bis substituted SnAP-eX reagents afforded racemic 2,3-disubstituted piperidines by using the standard conditions. ${ }^{2 f}$

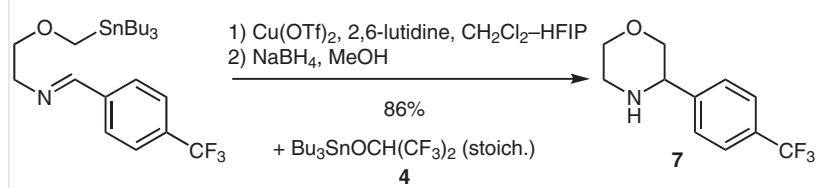

isolated side products: ${ }^{a}$

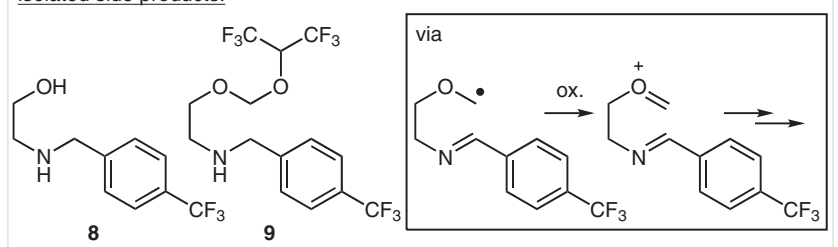

Scheme 3 Side product formation through an oxidative mechanism. a Dimeric structures were not detected in the crude ${ }^{1} \mathrm{H}$ NMR spectrum as confirmed through independent synthesis (see Supporting Information).

Organostannanes are known to undergo bond fragmentation upon one-electron oxidation giving an organic radical and a stannylium cation fragment, 10,11 a fragment that was previously isolated as the HFI -adduct 4 . $^{2 e}$ Not surprisingly, unsymmetrically substituted stannanes would lead to the formation of the most stable organic radical upon such oxidative fragmentations affording an $\alpha$ - heteroatom-stabilized alkyl radical by using SnAP reagents. Therefore, the postulated mechanistic picture (Scheme 2, b) in which the $\mathrm{C}-\mathrm{Sn}$ bond is oxidized through a $\mathrm{Cu}(\mathrm{II})$ species is proposed to involve an $\alpha$-heteroatom-stabilized carboncentered radical. Such a radical is proposed to react in an intramolecular reaction with the imine LUMO being located on the azomethine carbon forming a nitrogen-centered radical.

Trapping of such an open-shell intermediate would provide strong support for a radical cyclization. On the basis of this assumption and to provide further evidence that a free radical intermediate is generated during the SnAP reaction, radical clock experiments aimed at trapping the proposed nitrogen-centered radical were conducted. With the knowledge that the addition of $\mathrm{N}$-centered radicals onto alkenes in general is relatively slow, fragmentations that produce a relatively stable imine $\pi$-bond were investigated over the addition of $\mathrm{N}$-centered radicals onto olefins. ${ }^{12}$ To make sure that our radical indicator reactions are fast enough to compete with processes that intercept the proposed intermediates, an SnAP reagent for nitrogen radical fragmentation with known fast kinetics was designed. ${ }^{13}$

The unsubstituted cyclopropane analogue was synthesized in a short reaction sequence (Scheme 4). Starting from 1-amino-1-cyclopropane carboxylic acid, reduction, nitrogen protection, alkylation, and deprotection provided radical clock SnAP morpholine 14. To examine our hypothesis, an imine formed from the radical clock SnAP reagent 


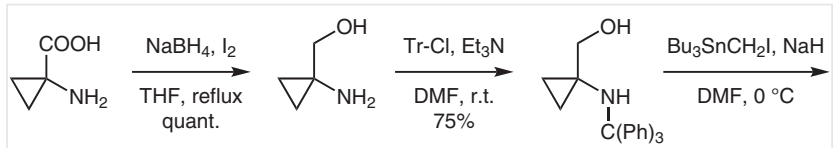
10 11 12

Scheme 4 Preparation of radical clock SnAP reagent

was employed under standard SnAP cyclization conditions. As ring opening of the cyclopropane would afford unstable imine products, $\mathrm{NaBH}_{4}$ reduction was performed on the crude material. Subsequent detection and isolation of ringopened products arising from either reduction 15 or oxidation 16 of the intermediate ring-opened radical reinforce the proposal of an open-shell SnAP cyclization (Scheme 5).

The structures of the isolated products were confirmed by their independent preparation (Scheme 6). The amino alcohol required for the synthesis of the vinyl SnAP reagent 23 was obtained through a diastereoselective addition of vinylmagnesium bromide to $\mathrm{N}$-sulfinyl imine $\mathbf{1 8}^{14}$ followed by simultaneous amine and alcohol deprotection. Cyclization using SnAP morpholine reagent 23 under the same conditions as in the radical clock experiment afforded cis2,6-disubstituted morpholine 16, confirming the structure of the ring-opened product isolated from the radical clock experiment (Scheme 6, a). Furthermore, SnAP 3-Vinyl M 23

demonstrates for the first time that the proposed nucleophilic $\alpha$-heteroatom-stabilized radical preferentially reacts in a 6-endo-trig manner with a $\mathrm{C}=\mathrm{N}$ double bond affording a stabilized nitrogen-centered radical which is preferred over the 5-exo-trig or 6-endo-trig addition onto an alkene. This is also observed for the preparation of medium-sized Nheterocycles with use of SnAP 3-Vinyl OA 24 by the 7-endotrig addition onto an imine which is preferred over the 5exo-trig or 6-endo-trig addition onto an internal alkene (Scheme 6, b).

The structure of cis-2,6-disubstituted morpholine $\mathbf{1 5}$ was confirmed in a short reaction sequence by using 2aminobutanol 26 (Scheme 6, c). By using a reported 0stannylmethylation procedure of $\alpha$-disubstituted aminoalcohols, ${ }^{15 b}$ SnAP 3-Et M 27 reagent was prepared in one step (Scheme 6, c). With use of the same cyclization conditions as in the radical clock experiment, cis-2,6-disubstituted morpholine 15 was obtained in $82 \%$, confirming the structure of the ring-opened product isolated from the radical clock experiment.

Finally, additional control experiments were performed to confirm that the ring-opened products are the direct results of a radical cyclization and subsequent cyclopropane fragmentation and test the stability of the cyclopropane scaffold under the reaction conditions applied (Scheme 7).

Destannylated starting material and side products arising from C-Sn bond oxidation were detected, but no ringopened products were observed when the radical clock SnAP 14 was subjected to the standard cyclization conditions without prior imine formation (Scheme 7, a). Substituting the labile $\mathrm{Bu}_{3} \mathrm{Sn}$ group in $\mathrm{SnAP} 14$ to remove a potential source of unwanted side reactions and focus on the

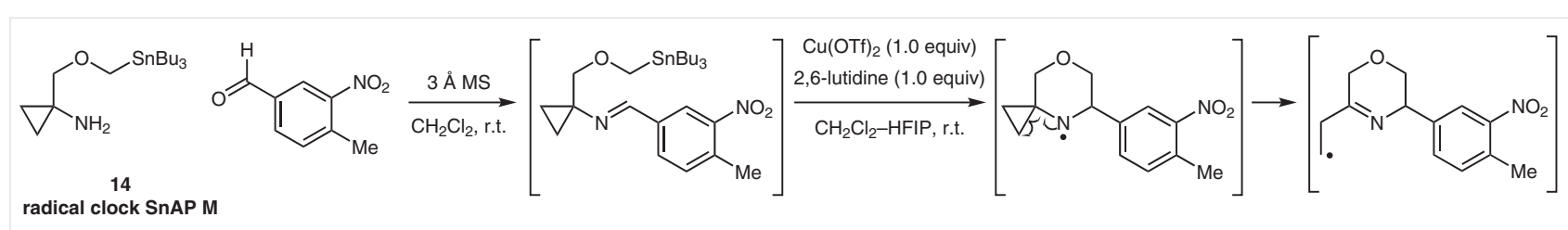

radical clock SnAP M

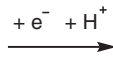<smiles>COc1ccc([C@@H]2COCC(C[N+](=O)[O-])=N2)cc1[N+](=O)[O-]</smiles>

$\stackrel{-\mathrm{e}^{-}-\mathrm{H}^{+}}{\longrightarrow}$<smiles>C=CC1=N[C@@H](c2ccc([N+](=O)[O-])c([N+](=O)[O-])c2)COC1</smiles>

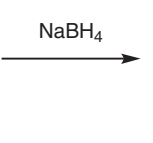

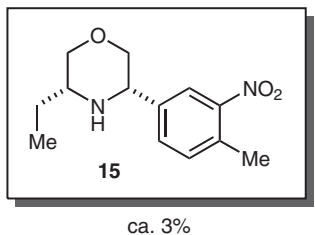

- No cyclized product with intact cyclopropyl detected

- Structures confirmed by independent synthesis

- Yields refer to isolated material

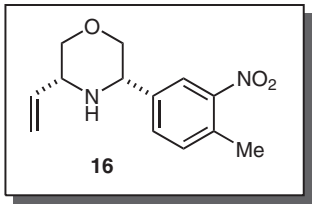

$10 \%$

Scheme 5 Radical clock SnAP reaction to detect nitrogen-centered radicals upon successful cyclization 


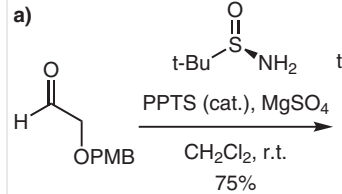

17

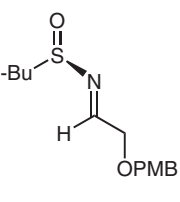

18

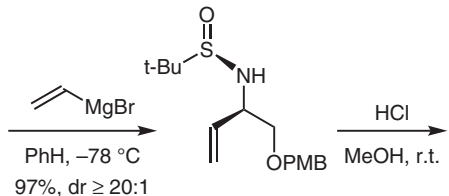

19

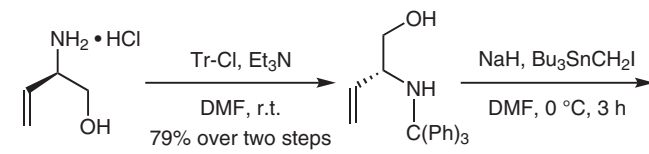

20
1) $\mathrm{RCHO}$

$\| \int_{\mathrm{C}(\mathrm{Ph})_{3}}^{\stackrel{\mathrm{AcOH}, \mathrm{TFE}}{\mathrm{NH}}} \stackrel{\mathrm{SnBu}_{3}}{\stackrel{\mathrm{CH}_{2} \mathrm{Cl}_{2} \text {, r.t. }}{\longrightarrow}}$

22

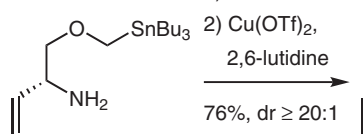

23

SnAP 3-Vinyl M

b)<smiles>CC[C@@H]1COC[C@H](c2ccc(C)c([N+](=O)[O-])c2)N1</smiles>

16

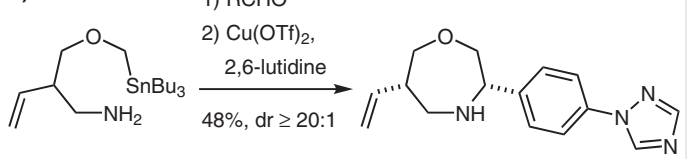

SnAP 3-Vinyl OA 7 steps $\left(40 \%\right.$ overall) ${ }^{\text {a }}$
25

- 3 New SnAP reagents

- Cyclization products are idential to isolated materials in the radical clock experiments

- 6- And 7-endo-trig cyclization onto imine preferred over 5-exoor 6-endo-trig cyclization onto olefins

c)<smiles>CCC(N)CO</smiles>
26

$$
\text { 27 } \stackrel{2,6 \text {-lutidine }}{\stackrel{82 \%, d r \geq 20: 1}{\longrightarrow}}
$$$$
\text { 1) } \mathrm{RCHO}
$$<smiles>CC[C@H]1COC[C@H](c2ccc(C)c([N+](=O)[O-])c2)N1</smiles>

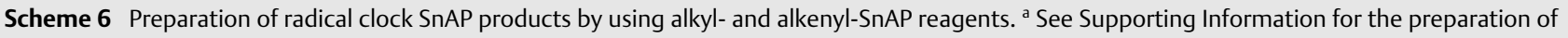
SnAP 3-Vinyl OA 24

a) Radical clock SnAP reagent stability test

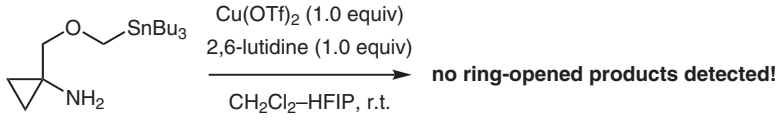

14

b) Radical clock SnAP analogue stability test

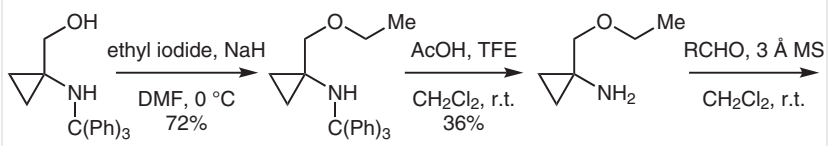

$$
\begin{aligned}
& 12 \\
& \begin{array}{c}
29 \\
\text { volatile }
\end{array}
\end{aligned}
$$<smiles>COCC1(/N=C/c2ccc(C)c([N+](=O)[O-])c2)CC1</smiles>

$\mathrm{Cu}(\mathrm{OTf})_{2}, 2,6$-lutidine, $\mathrm{CH}_{2} \mathrm{Cl}_{2}-\mathrm{HFIP}$, r.t.

or 1) $\mathrm{NaBH}_{4}, \mathrm{MeOH}$

2) $\mathrm{Cu}(\mathrm{OTf})_{2}, 2,6$-lutidine, $\mathrm{CH}_{2} \mathrm{Cl}_{2}-\mathrm{HFIP}$, r.t.

no ring-opened products detected!

Scheme 7 Cyclopropane imine stability studies under SnAP cyclization conditions. These results demonstrate that SnAP reactions are not induced by redox reactions of the imine.

stability of the imine and secondary amine of potential product, (ethoxymethyl)cyclopropanamine $\mathbf{2 9}$ was prepared (Scheme 7, b). No cyclopropane fragmentation was observed by using $\mathbf{2 9}$ either as the imine or as the secondary amine after imine reduction, again supporting our proposal of a radical-based SnAP cyclization.

Considering the above results and the additional properties of HFIP to assist in intermolecular electron-transfer reactions through stabilization of radical cations, which extends their lifetime and facilitates subsequent fragmentations, ${ }^{16}$ through an HFIP nucleophile-assisted cleavage of a stannane radical cation, ${ }^{17}$ also seen in organosilane-cation radicals, ${ }^{18}$ strong support is found for the current proposal of a radical cyclization using SnAP reagents (Scheme 2, b). The fact that little conversion is observed without the addition of HFIP2a and the finding that $\mathrm{Bu}_{3} \mathrm{Sn}-\mathrm{OCH}\left(\mathrm{CF}_{3}\right)_{2} 4$ is formed in a 1:1 ratio to the desired N-heterocycle ${ }^{2 \mathrm{e}}$ further reinforce this mechanistic proposal, which might also be driven by the formation of the thermodynamically strong Sn-O bond (ca. $550 \mathrm{~kJ} \mathrm{~mol}^{-1}$ ) vs. Sn-C (ca. $235 \mathrm{kj} \mathrm{mol}^{-1}$ ) that could facilitate fragmentation. ${ }^{19}$

In conclusion, several observations documented in these studies are consistent with the initial mechanistic proposal of the SnAP protocol as a radical-based method. ${ }^{20}$ As $\mathrm{Cu}(\mathrm{OTf})_{2}$ is known to be a source of triflic acid, investigations on the role of a Brønsted acid-mediated mechanism allowed us to exclude this, as well as a Lewis acid-mediated process. Taken together, the further evidence of the radicalbased nature of SnAP chemistry will guide ongoing efforts to develop new variants and selective catalysts. 


\section{Funding Information}

This work was supported by the European Research Council (ERC Starting Grant No. 306793-CASAA).

\section{Acknowledgment}

We thank the MS Service and NMR Service of the Laboratory of Organic Chemistry at ETH Zurich for analysis.

\section{Supporting Information}

Supporting information for this article is available online at https://doi.org/10.1055/s-0037-1611670.

\section{References and Notes}

(1) Present address: Michael. U. Luescher, Department of Chemistry and Chemical Biology (CCB), Harvard University, Cambridge, MA 02138, United States of America

(2) (a) Vo, C.-V. T.; Mikutis, G.; Bode, J. W. Angew. Chem. Int. Ed. 2013, 52, 1705. (b) Luescher, M. U.; Vo, C.-V. T.; Bode, J. W. Org. Lett. 2014, 16, 1236. (c) Vo, C.-V. T.; Luescher, M. U.; Bode, J. W. Nat. Chem. 2014, 6, 310. (d) Geoghegan, K.; Bode, J. W. Org. Lett. 2015, 17, 1934. (e) Luescher, M. U.; Bode, J. W. Angew. Chem. Int. Ed. 2015, 54, 10884. (f) Luescher, M. U.; Bode, J. W. Org. Lett. 2016, 18, 2652.

(3) Hideto, M.; Ueda, M.; Naito, T. Synlett 2004, 1140.

(4) Jindakun, C.; Hsieh, S.-Y.; Bode, J. W. Org. Lett. 2018, 20, 2071.

(5) Paderes, M. C.; Belding, L.; Fanovic, B.; Dudding, T.; Keister, J. B.; Chemler, S. R. Chem. Eur. J. 2012, 18, 1711.

(6) Vogler, T.; Studer, A. Synthesis 2008, 1979.

(7) Michel, C.; Belanzoni, P.; Gamez, P.; Reedjik, J.; Baerends, E. J. Inorg. Chem. 2009, 48, 11909.

(8) (a) Youn, S. W.; Jang, S. S.; Lee, S. R. Tetrahedron 2016, 72, 4902. (b) Dang, T. T.; Boeck, F.; Hintermann, L. J. Org. Chem. 2011, 76, 9353. (c) Tschan, M. J.-L.; Thomas, C. M.; Strub, H.; Carpentier, J.-F. Adv. Synth. Catal. 2009, 351, 2496. (d) Wabnitz, T. C.; Yu, J.-Q.; Spencer, J. B. Chem. Eur. J. 2004, 10, 484.

(9) Brown, H. C.; Kanner, B. J. Am. Chem. Soc. 1966, 88, 986.

(10) Luo, P.; Dinnocenzo, J. P. J. Org. Chem. 2015, 80, 9240.

(11) (a) Yoshida, J.-I.; Kataoka, K.; Horcajada, R.; Nagaki, A. Chem. Rev. 2008, 108, 2265. (b) Glass, R. S.; Radspinner, A. M.; Singh, W. P. Tetrahedron 1992, 114, 4921. (c) Yoshida, J.-I.; Ishichi, Y.; Nishiwaki, K.; Shiozawa, S.; Isoe, S. Tetrahedron Lett. 1992, 33, 2599. (d) Yoshida, J.-I.; Maekawa, T.; Murata, T.; Matsunaga, S.-I.; Isoe, S. J. Am. Chem. Soc. 1990, 112, 1962.

(12) Musa, O. M.; Horner, J. H.; Shahin, H.; Newcomb, M. J. Am. Chem. Soc. 1996, 118, 3862.

(13) (a) Newcomb, M. Encyclopedia of Radicals in Chemistry, Biology and Materials; Vol. 1; Chatgilialoglu, C.; Studer, A., Eds.; Wiley: Chichester, UK, 2012, 107-124. (b) Beckwith, A. L. J.; Bowry, V. W. J. Am. Chem. Soc. 1994, 116, 2710. (c) Newcomb, M. Tetrahedron 1993, 49, 1151. (d) Griller, D.; Ingold, K. U. Acc. Chem. Res. 1980, 13, 317.

(14) (a) Chen, Y.; Goldberg, F. W.; Xiong, J.; Wang, S. Synthesis 2015, 47, 679. (b) Crimmins, M. T.; Shamszad, M. Org. Lett. 2007, 9, 149. (c) Barrow, J. C.; Ngo, P. L.; Pellicore, J. M.; Selnick, H. G.; Nantermet, P. G. Tetrahedron Lett. 2001, 42, 2051. (d) Tang, T. P.; Volkman, S. K.; Ellman, J. A. J. Org. Chem. 2001, 66, 8772.
(15) (a) Luescher, M. U.; Jindakun, C.; Bode, J. W. Org. Synth. 2018, 95, 345. (b) Luescher, M. U.; Jindakun, C.; Bode, J. W. Org. Synth. 2018, 95, 357.

(16) (a) Yoshida, J.-I.; Kataoka, K.; Horcajada, R.; Nagaki, A. Chem. Rev. 2008, 108, 2265. (b) Yoshida, J.-I.; Izawa, M. J. Am. Chem. Soc. 1997, 119, 9361. (c) Eberson, L.; Hartshorn, M. P.; Persson, O.; Radner, F. Chem. Commun. 1996, 2105.

(17) Luo, P.; Dinnocenzo, J. P. J. Org. Chem. 2015, 80, 9240.

(18) Dockery, K. P.; Dinnocenzo, J. P.; Farid, S.; Goodman, J. L.; Gould, I. R.; Todd, W. P. J. Am. Chem. Soc. 1997, 119, 1876.

(19) Dean, J. A. In Lange's Handbook of Chemistry; McGraw-Hill: New York, 1999, 15th ed., 4.41-4.53.

(20) General Procedure SnAP Protocol

Imine formation: To a solution of the SnAP reagent $(0.50$ mmol, 1.00 equiv) in $\mathrm{CH}_{2} \mathrm{Cl}_{2}$ or acetonitrile $(3.0 \mathrm{~mL})$ at r.t. was added the corresponding aldehyde $(0.50 \mathrm{mmol}, 1.00$ equiv) and $3 \AA$ Å or $4 \AA$ MS powder (ca. $50 \mathrm{mg}$ ). The reaction mixture was stirred at r.t. for $4 \mathrm{~h}$ and filtered through a short layer of Celite $\left(\mathrm{CH}_{2} \mathrm{Cl}_{2}\right.$ rinse). The filtrate was concentrated under reduced pressure to afford the pure air-stable imine that was used in the next step without further purification.

SnAP cyclization: Separately, anhydrous $\mathrm{Cu}(\mathrm{OTf})_{2}(0.50 \mathrm{mmol}$, 1.00 equiv) was suspended in $\mathrm{CH}_{2} \mathrm{Cl}_{2}$-HFIP $(3: 1 ; 8.0 \mathrm{~mL}) .2,6-$ Lutidine ( $0.50 \mathrm{mmol}, 1.00$ equiv) was added and the resulting bluish suspension was stirred at r.t. for $1 \mathrm{~h}$ to afford a dark green suspension. A solution of the imine $(0.50 \mathrm{mmol}, 1.00$ equiv $)$ in $\mathrm{CH}_{2} \mathrm{Cl}_{2}(2.0 \mathrm{~mL})$ was added in one portion and the resulting mixture was stirred at r.t. for $12 \mathrm{~h}$. The reaction mixture was diluted with $\mathrm{CH}_{2} \mathrm{Cl}_{2}(20 \mathrm{~mL})$, treated with a solution of $12 \%$ aq $\mathrm{NH}_{4} \mathrm{OH}$ and brine $(1: 1,20 \mathrm{~mL})$, and stirred vigorously for $20 \mathrm{~min}$ at r.t. The layers were separated, and the aqueous layer was extracted with $\mathrm{CH}_{2} \mathrm{Cl}_{2}(2 \times 5 \mathrm{~mL})$. The combined organic layers were washed with $\mathrm{H}_{2} \mathrm{O}(2 \times 5 \mathrm{~mL})$ and brine $(10 \mathrm{~mL})$, dried with anhydrous $\mathrm{Na}_{2} \mathrm{SO}_{4}$, filtered, and concentrated. Purification by flash column chromatography afforded the desired C-substituted unprotected morpholines.

Spectral Data for Selected Compounds

3-(4-(Trifluoromethyl)phenyl)morpholine (7): Yield: $98.5 \mathrm{mg}$ (86\%); clear colorless oil; IR (thin film): 3313, 3068, 2961, 2912, 2889, 2852, 1676, 1603, 1584, 1398, 1365, 1335, 1232, 1105 $\mathrm{cm}^{-1} ;{ }^{1} \mathrm{H}$ NMR $\left(400 \mathrm{MHz}, \mathrm{CDCl}_{3}\right): \delta=7.59(\mathrm{~d}, J=8.2 \mathrm{~Hz}, 2 \mathrm{H})$, $7.52(\mathrm{~d}, J=8.2 \mathrm{~Hz}, 2 \mathrm{H}), 3.99$ (dd, $J=10.0,3.2 \mathrm{~Hz}, 1 \mathrm{H}), 3.93-3.85$ $(\mathrm{m}, 1 \mathrm{H}), 3.81(\mathrm{dd}, J=11.1,3.2 \mathrm{~Hz}, 1 \mathrm{H}), 3.65(\mathrm{td}, J=11.1,2.7 \mathrm{~Hz}$, $1 \mathrm{H}), 3.35$ (dd, $J=11.1,10.0 \mathrm{~Hz}, 1 \mathrm{H}), 3.14(\mathrm{td}, J=11.6,3.3 \mathrm{~Hz}, 1$ $\mathrm{H}), 3.01(\mathrm{dt}, J=11.8,2.0 \mathrm{~Hz}, 1 \mathrm{H}), 1.90(\mathrm{br} \mathrm{s}, \mathrm{NH}) ;{ }^{13} \mathrm{C}$ NMR $(100$ $\left.\mathrm{MHz}, \mathrm{CDCl}_{3}\right): \delta=144.7\left(\mathrm{q}, J_{C F}=1.40 \mathrm{~Hz}\right), 130.1\left(\mathrm{q}, J_{C F}=32.4 \mathrm{~Hz}\right)$, 127.7, $125.6\left(\mathrm{q}, J_{C F}=3.72 \mathrm{~Hz}\right), 124.2\left(\mathrm{q}, J_{C F}=272.2 \mathrm{~Hz}\right), 73.6$, 67.4, 60.3, 46.5; $R_{f}=0.18$ (hexanes/EtOAc 1:1); ESI-HRMS: $\mathrm{m} / \mathrm{z}$ $[\mathrm{M}+\mathrm{H}]$ calcd for $\mathrm{C}_{11} \mathrm{H}_{13} \mathrm{~F}_{3} \mathrm{~N}_{1} \mathrm{O}_{1}: 232.0944$; found: 232.0946 . (士)-cis-3-Ethyl-5-(4-methyl-3-nitrophenyl) morpholine (15): Yield: $102 \mathrm{mg}(82 \%$, d.r. > 20:1); colorless oil; IR (thin film): 2963, 2932, 2878, 2848, 1528, 1454, 1349, $1105 \mathrm{~cm}^{-1} ;{ }^{1} \mathrm{H}$ $\operatorname{NMR}\left(400 \mathrm{MHz}, \mathrm{CDCl}_{3}\right): \delta=8.03(\mathrm{~d}, J=1.8 \mathrm{~Hz}, 1 \mathrm{H}), 7.52(\mathrm{dd}, J=$ $7.9,1.8 \mathrm{~Hz}, 1 \mathrm{H}), 7.29$ (d, $J=7.9 \mathrm{~Hz}, 1 \mathrm{H}), 4.01$ (dd, $J=10.2,3.2$ $\mathrm{Hz}, 1 \mathrm{H}), 3.84(\mathrm{dd}, J=10.9,3.0 \mathrm{~Hz}, 1 \mathrm{H}), 3.78(\mathrm{dd}, J=11.0,3.2 \mathrm{~Hz}$, $1 \mathrm{H}), 3.28-3.14(\mathrm{~m}, 2 \mathrm{H}), 2.96-2.85$ (m, $1 \mathrm{H}), 2.56$ (s, $3 \mathrm{H}), 1.89$ (br s, NH), 1.50-1.27 (m, $2 \mathrm{H}), 0.94(\mathrm{t}, J=7.5 \mathrm{~Hz}, 3 \mathrm{H}) ;{ }^{13} \mathrm{C}$ NMR $\left(100 \mathrm{MHz}, \mathrm{CDCl}_{3}\right): \delta=149.5,147.4,140.3,132.9,132.7,132.0$, $123.4,73.2,72.0,59.7,56.8,25.5,20.2,10.1 ; R_{f}=0.30$ (hexanes/EtOAc 1:1); ESI-HRMS: $m / z[\mathrm{M}+\mathrm{H}]^{+}$calcd for $\mathrm{C}_{13} \mathrm{H}_{19} \mathrm{~N}_{2} \mathrm{O}_{3}$ : 251.1390; found: 251.1394 . 
(3S,5R)-3-(4-Methyl-3-nitrophenyl)-5-vinylmorpholine (16): Yield: $94.4 \mathrm{mg}$ (76\%, d.r. > 20:1); colorless oil; IR (thin film): 2988, 2849, 1738, 1528, 1275, 1261, $1102 \mathrm{~cm}^{-1}$; ${ }^{1} \mathrm{H}$ NMR (400 $\left.\mathrm{MHz}, \mathrm{CDCl}_{3}\right): \delta=8.06(\mathrm{~d}, J=1.8 \mathrm{~Hz}, 1 \mathrm{H}), 7.55(\mathrm{dd}, J=7.9,1.8 \mathrm{~Hz}$, $1 \mathrm{H}$ ), 7.30 (d, $J=7.9 \mathrm{~Hz}, 1 \mathrm{H}$ ), 5.77 (ddd, $J=17.3,10.4,6.8 \mathrm{~Hz}, 1$ $\mathrm{H}), 5.35(\mathrm{dt}, J=17.3,1.4 \mathrm{~Hz}, 1 \mathrm{H}), 5.23-5.12(\mathrm{~m}, 1 \mathrm{H}), 4.07(\mathrm{dd}$, $J=10.2,3.2 \mathrm{~Hz}, 1 \mathrm{H}$ ), 3.81 (td, $J=10.4,3.2 \mathrm{~Hz}, 2 \mathrm{H}$ ), 3.65-3.50 (m, $1 \mathrm{H}), 3.33-3.19(\mathrm{~m}, 2 \mathrm{H}), 2.58$ (s, 3H), 1.93 (br s, NH); ${ }^{13} \mathrm{C}$ NMR $\left(100 \mathrm{MHz}, \mathrm{CDCl}_{3}\right): \delta=149.5,140.1,136.5,133.1,133.0$, $132.0,123.5,117.6,72.9,71.3,59.2,58.6,20.3 ; R_{f}=0.68$ (hexanes/EtOAc 1:1); ESI-HRMS: $m / z[\mathrm{M}+\mathrm{H}]^{+}$calcd for $\mathrm{C}_{13} \mathrm{H}_{17} \mathrm{~N}_{2} \mathrm{O}_{3}$ : 249.1234; found: 249.1231 .
(士)-cis-3-[4-(1H-1,2,4-Triazol-1-yl)phenyl]-6-vinyl-1,4-oxazepane (25): Yield: $64.5 \mathrm{mg}$ (48\%, d.r. > 20:1); colorless oil; IR (thin film): 3433, 2938, 2857, 1638, 1522, 1280, 1144, 983, 836 $\mathrm{cm}^{-1} ;{ }^{1} \mathrm{H} \mathrm{NMR}\left(400 \mathrm{MHz}, \mathrm{CDCl}_{3}\right): \delta=8.53(\mathrm{~s}, 1 \mathrm{H}), 8.09(\mathrm{~s}, 1 \mathrm{H})$, $7.63(\mathrm{~d}, J=8.5 \mathrm{~Hz}, 2 \mathrm{H}), 7.51(\mathrm{~d}, J=8.5 \mathrm{~Hz}, 2 \mathrm{H}), 5.91$ (ddd, $J=$ 17.3, 10.5, 8.1 Hz, $1 \mathrm{H}), 5.14-5.00(\mathrm{~m}, 2 \mathrm{H}), 4.13-3.97(\mathrm{~m}, 3 \mathrm{H})$, 3.56 (dd, $J=12.4,9.6 \mathrm{~Hz}, 1 \mathrm{H}), 3.43$ (dd, $J=13.0,10.5 \mathrm{~Hz}, 1 \mathrm{H}$ ), $3.24(\mathrm{dd}, J=13.9,4.9 \mathrm{~Hz}, 1 \mathrm{H}), 3.12(\mathrm{dd}, J=13.9,3.5 \mathrm{~Hz}, 1 \mathrm{H})$, 2.77-2.66 (m, $1 \mathrm{H}), 2.09$ (br s, NH); ${ }^{13} \mathrm{C} \mathrm{NMR}\left(100 \mathrm{MHz}, \mathrm{CDCl}_{3}\right): \delta$ $=152.7,141.6,141.0,138.8,136.4,128.6,120.3,115.6,80.6$, 75.5, 66.3, 51.9, 47.2; $R_{f}=0.21$ (hexanes/EtOAc 2:1); $\mathrm{mp}=70-$ $72{ }^{\circ} \mathrm{C}$; ESI-HRMS: $m / z$ [M $\left.+\mathrm{H}\right]^{+}$calcd for $\mathrm{C}_{14} \mathrm{H}_{19} \mathrm{~N}_{4} \mathrm{O}_{1}: 271.1553$; found: 271.1558 